\title{
Dutch Economists Top 40
}

\author{
Jaap H. Abbring* Bart J. Bronnenberg ${ }^{\dagger}$ Pieter A. Gautier ${ }^{\ddagger}$ Jan C. van Ours ${ }^{\S}$
}

April 3, 2014

\begin{abstract}
There is a tradition in the Netherlands to publish an annual ranking of economic and business researchers working in Dutch universities. The most recent such ranking, published in 2013, emphasizes research quantity over research quality. We propose an alternative ranking based on quality. Important information about a researcher's quality and impact is lost when moulding it to fit a template of numbers. Our ranking is no exception. Nevertheless, we argue and demonstrate that our ranking fits international consensus on research prominence and that the 2013 ranking does not.
\end{abstract}

Keywords: business research, Dutch universities, economic research, ranking, research policy JEL: I23

\footnotetext{
${ }^{*}$ CentER, Department of Econometrics \& OR, Tilburg University. Email: jaap@abbring.org.

${ }^{\dagger}$ CentER, Department of Marketing, Tilburg University. Email: bart.bronnenberg@uvt.nl.

${ }^{\ddagger}$ Department of Economics, VU University Amsterdam. Email: p.a.gautier@vu.nl.

${ }^{\S}$ CentER, Department of Economics, Tilburg University; Department of Economics, University of Melbourne; and CEPR. Email: vanours@uvt.nl.
} 


\section{Introduction}

Research universities compete for resources and rankings are used by many university departments as a way to help allocate resources. In addition, research staff and faculty members themselves compete for resources, students, and recognition. This gives them an incentive to play by the ranking rules in use at their own universities or at a national level. The rules under which a ranking is made are thus not completely unimportant.

In the Netherlands ranking of economists goes back to $1980 .{ }^{1}$ The ranking is an annual folklore that provides a modicum of diversion among Dutch academics. The list is taken none too seriously by any scholar. The data underlying these rankings are poor measures of the underlying quality of research ideas and thought-leadership pursued in the papers published, and no ranking method, using these data diligently or otherwise, can cure this ill. Therefore, we believe that any ranking should be met with considerable reticence, including the one we propose here.

The latest ranking of economists and business researchers working in Dutch universities was published in December 2013 in ESB (Phlippen, 2013). This latest ranking underwent an important methodological change in comparison to previous rankings. This change was decided upon in a meeting of the joint deans of Dutch economics departments. The new method focuses heavily on quantity of publications. Our concern is that if quantity of publications is made a dominant feature of the reward system, it is reasonable to expect that the "system" will respond in the direction of either spawning or hiring a generation of researchers interested in writing many publications. We find this undesirable and are worried that this will come at the expense of quality, will degrade academic activity to publishing contests, and will promote thin-slicing one's research.

\footnotetext{
${ }^{1}$ See Van Ours and Vermeulen (2007) for a short history. Economists are ranked in other countries as well; see for example Dolado et al. (2003) and Bauwens (2007).
} 
We propose an alternative ranking that features a stronger reliance on the quality of the journals, uses a cap on the number of publications that counts in the ranking, and focuses on full-length articles. ${ }^{2}$ We compare how recent winners of the John Bates Clark Medal, awarded annually to a single thought-leading U.S. based economist under 40, fare on the ESB ranking versus the new ranking.

\section{The rules of the ESB and the alternative ranking}

The ESB ranking is based on a single publication score for each researcher from his/her publications over a recent 5-year time horizon. The score for a researcher $i$ publishing articles $n=1, \ldots, N_{i}$ in the 5-year period, is the sum of weights

$$
S_{i}=\sum_{n=1}^{N_{i}} w_{i, n}^{j} w_{i, n}^{a}
$$

where $w_{i, n}^{j}$ is a journal weight for researcher $i$ 's $n$th article obtained from the Eigenfactor.org project at the University of Washington (West and Bergstrom, 2013), and $w_{i, n}^{a}$ corrects for the number of authors $c_{i, n}$ of that same article using the rule

$$
w_{i, n}^{a}=\frac{2}{1+c_{i, n}} .
$$

The major change in the 2013 ESB ranking involved abandoning the Article Influence Score (AIS) as a measure for $w_{i, n}^{j}$ in favor of the Percentile Score (PRS) at Eigenfactor.org. The difference is that the latter is a much less concentrated measure of quality.

To make this point clear, take the following example involving two journals, the Quar-

\footnotetext{
${ }^{2}$ Also earlier ranking procedures to generate a Dutch economists Top 40 have been criticized. Van Ours and Vermeulen (2007) using 2006 Top 40 data show that a quality oriented ranking generates substantially different results than a quantity oriented ranking.
} 
terly Journal of Economics and Economics Letters. From the publisher statement, Quarterly Journal of Economics is the "oldest professional journal of economics in the English language. Edited at Harvard University's Department of Economics, it covers all aspects of the field." Being one of a handful of premier economics journals, it publishes fulllength articles of typically 20-35 pages that communicate large-scale research that took teams of 1-3 economists often 4-5 years to complete. During this admittedly lengthy period, researchers write and revise the paper and they typically present the paper and test its underlying ideas at departmental seminars in other schools (often 10 times or more), and at conferences. This generates debate and peer-assessment among interested colleagues. When it finally gets published by the Quarterly Journal of Economics, the paper typically already has a following among specialists; the nature of the journal as serving a general interest audience of economists only makes this following larger. Empirically, such a publication has a high chance of being influential, well cited, and of general interest to economists.

The journal Economics Letters fulfills a fundamentally different purpose. ${ }^{3}$ From its website, it aims to be "a valuable addition to the specialist literature, offering quick dissemination and easy accessibility of new results, models and methods in all fields of economic research." Typically this journal publishes short papers, 3-4 pages, on ideas that are often too specific to be of general interest. The production process of these "notes" is usually much shorter and the impact of this journal in terms of citations and influence is commensurate.

The Article Influence Score seeks to measure the difference in influence across journals such as the Quarterly Journal of Economics and Economics Letters by tracking the

\footnotetext{
${ }^{3}$ We could have taken many other journals for comparison. We chose Economics Letters because it is well known and many scholars in the ESB data base have published in it. The implication is not that one journal is good and other is bad, but rather that by design they have very different impacts on research and field knowledge and that the AIS captures this better than the PRS.
} 
citations of a typical paper in it. However, not every citation is counted equally. That is, citations from journals that have a higher influence score are weighed more so that "highly cited journals will influence the network more than lesser cited journals. References from one article in a journal to another article from the same journal are removed, so that [scores] are not influenced by journal self-citation" (West and Bergstrom (2013); see also Neary et al. (2003)). At an intuitive level, the AIS captures per-article citation behavior to a focal journal from citing journals only, taking into account the prestige of the citing journals.

Unsurprisingly, the AIS is highly skewed. There are many more journals with a low AIS than there are with a high AIS score. In contrast, the PRS is intended to avoid this skew by looking only at the AIS-rank of journals. That is, the PRS expresses the fraction of journals with a lower AIS than the journal itself. Going back to the example, the Quarterly Journal of Economics has an AIS of 12.3 and a PRS of 0.996. Thus, it has a higher AIS than $99.6 \%$ of academic journals. To compare, Economics Letters has an AIS of 0.575 and a PRS of 0.537 . The AIS ratio between the two journals is more than 20 , whereas the PRS ratio is less than 2 .

The latest ESB ranking uses the percentile score. In this ranking, therefore, two Economics Letters lead to a higher score than a single publication in the Quarterly Journal of Economics, or any other journal. We do not believe that this weighting reflects the differences in influence and impact of the underlying research endeavor. If it did, why are most top economists not abandoning the premier journals at the benefit of journals with a lower AIS? As noted before, this is not to slight at Economics Letters, which is a fine journal that serves its stated purpose well.

Like the ESB ranking, our ranking is based on numerical productivity statistics and involves making subjective choices, which we list in Table 1. We motivate these choices 
next. First, we use the same basic data as the ESB ranking. ${ }^{4}$ To these data we have added the records of a handful of Dutch economists who published in the top economics journals during the 2008-2012 period. ${ }^{5}$ One may wonder why these researchers were absent from the ESB data base in the first place. The simple answer is that each university submits a maximum of 20 names of research faculty to be included in the ESB ranking and universities apparently choose those researchers that they anticipate will do best on the ESB criteria. ${ }^{6}$ Oddly, in at least a few cases, this led universities to ignore scholars who publish in the leading general interest journals. Second, from these data we retain only those publications that are classified as "articles" in the ESB data base and drop "notes," "letters," and the like. ${ }^{7}$ With this rule, we want to avoid the scenario where a twoparagraph published letter to a journal editor receives the same merit in ranking as a full length research article. ${ }^{8}$ Next, we use the AIS as an imperfect surrogate for publication quality and impact. Our justification, illustrated with the example above, is that it is a better proxy than PRS. Fourth, quantity and quality of publications form a trade-off in the sense of being produced against a common time constraint. Consequently, we feel it is desirable to introduce decreasing marginal returns to quantity of publications. The simplest way of doing so is to cap the number of publications counted in the ranking. In particular, we use for each researcher the highest scoring articles over the 2008-2012 period with a maximum 15 publications in total. We lack a clear justification for this number other than a "feeling" that it is unrealistic to expect a good researcher to publish more than 3 high quality papers in any given year. Finally, to remain consistent with the ranking's intent

\footnotetext{
${ }^{4}$ We are indebted to Sandra Phlippen for letting us use the data compiled for the ESB ranking.

${ }^{5}$ In particular, we screened on publications in the top five general interest journals: the American Economic Review, Econometrica, the Journal of Political Economy, the Quarterly Journal of Economics, and the Review of Economic Studies.

${ }^{6}$ This is a direct example of how the system responds to the rules.

${ }^{7} \mathrm{~A}$ few publications in the ESB data base had multipe classifications such as "Article; Proceedings Paper" or "Article; Book Chapter". These publications were treated as articles.

${ }^{8} \mathrm{We}$ comment below on the ranking with a more inclusive list.
} 


\begin{tabular}{|c|c|c|}
\hline Criteria & ESB ranking 2013 & Alternative ranking \\
\hline 1. Time span & $2008-2012$ & $2008-2012$ \\
\hline 2. Publication types & $\begin{array}{l}\text { articles, comments, letters, notes, } \\
\text { reviews, proceedings }\end{array}$ & articles \\
\hline 3. Publication weight & percentile scores (PRS) & article impact scores (AIS) \\
\hline 4. Number & no limit & 15 \\
\hline 5. Appointment & $\geq 20 \%$ of full time employment & $\geq 50 \%$ of full time employment \\
\hline
\end{tabular}

Table 1: Rules of the rankings

to reflect scholars working in the Netherlands, we only count those who have at least a $50 \%$ appointment in a Dutch university. Like all journal rankings this one also has some drawbacks, i.e. general articles in the American Economic Review have a relatively low impact due to the inclusion of papers and proceedings and Experimental Economics has a relatively high impact due to one article on a software package.

\section{Results}

Columns (1) and (2) of Table 2 give the result of the new ranking. Leading in the ranking that is based on a maximum of 15 full-length articles (in the column headed by "Articles only") is Erwin Bulte (Wageningen), and a close second is Daan van Knippenberg (Rotterdam). The top 3 is completed by Arthur van Soest (Tilburg). This ranking contains many excellent researchers, each with publications in the top journals of their fields. Actually, the list with researchers publishing in their top field journals extends well beyond the top 40. As shown in column (3), when we relax the rule of including only articles and allow for a broader set of publication types by removing the restriction to full length articles, the top 3 is headed by Arthur van Soest, with Daan van Knippenberg second and Bernard Nijstad third. 
It would be interesting to relate the differences between schools to variation in the role of top publications in their research, faculty recruitment, and faculty retainment policies. This is beyond the scope of this small paper because we lack good historical data on such policies across schools.

The two rule changes that cause the big shifts with the ESB ranking are (1) introducing decreasing marginal effects of quantity and (2) using the AIS score. For instance, columns (4) and (5) of Table 2 lists the ranking when we remove the rule of capping the number of publications completely. The top 10 now contains several new names of researchers who strike a balance that includes more publications, but with (sometimes) lower influence scores.

The rule about appointment being at least $50 \%$ of full time employment has some effect also. In particular, it removes a number of high ranking economists whose primary appointment is outside the Netherlands, such as Bart Hobijn (Federal Reserve Bank of San Francisco), Rick van der Ploeg (Oxford University), Richard Tol (University of Sussex), and a handful researchers with a small part-time appointment.

Column (6) of Table 2 replicates the ranking in the ESB top 40 for the researchers in our top 40. It is striking that almost half of the researchers in the ESB top 40 is not present in our ranking. Perhaps even more striking is the fact that of the ESB top 10 only 2 researchers are present in our Top 40. An obvious characteristic of our ranking is the difference in placement of some highly prolific writers. As noted by ESB, some economists published as many as 20 papers in a given year. In effect, not all of these researchers are in the top 40 of our ranking. More fundamentally, we question the desirability of such a high publishing rate for young ambitious Dutch economists.

To make this point more succinctly, consider the most prestigious recognition for young American economists, the John Bates Clark Medal. This prize is given annually to "that American economist under the age of forty who is judged to have made the most 


\begin{tabular}{|c|c|c|c|c|c|c|c|}
\hline & & & $\begin{array}{r}\text { Ranks u } \\
\text { of } 15\end{array}$ & $\begin{array}{l}\text { g maximum } \\
\text { blications }\end{array}$ & $\begin{array}{r}\text { Ranks } \\
\text { publ }\end{array}$ & $\begin{array}{l}\text { ssing all } \\
\text { ations }\end{array}$ & $\begin{array}{c}\text { Ranking } \\
\text { ESB }\end{array}$ \\
\hline & & Score & Articles & All types & Articles & All types & Top 40 \\
\hline Name & Uni & (1) & (2) & (3) & (4) & $(5)$ & (6) \\
\hline Erwin Bulte & WUR & 27.27 & 1 & 4 & 2 & 4 & 14 \\
\hline Daan van Knippenberg & EUR & 27.26 & 2 & 2 & 1 & 1 & 4 \\
\hline Arthur van Soest & UvT & 24.34 & 3 & 1 & 4 & 2 & 16 \\
\hline Harry Huizinga & UvT & 22.96 & 4 & 6 & 7 & 8 & - \\
\hline Bernard Nijstad & RUG & 21.44 & 5 & 3 & 6 & 3 & 19 \\
\hline John Einmahl & UvT & 21.40 & 6 & 7 & 10 & 12 & 28 \\
\hline Bart Bronnenberg & UvT & 19.59 & 7 & 9 & 13 & 15 & - \\
\hline Siem Jan Koopman & VU & 19.54 & 8 & 10 & 8 & 10 & 21 \\
\hline Jaap Abbring & UvT & 19.44 & 9 & 11 & 14 & 16 & - \\
\hline Rik Pieters & UvT & 19.42 & 10 & 12 & 5 & 6 & 13 \\
\hline Albert Menkveld & VU & 19.21 & 11 & 13 & 15 & 17 & - \\
\hline Peter Wakker & EUR & 18.65 & 12 & 15 & 11 & 13 & 23 \\
\hline Jan Magnus & UvT & 18.55 & 13 & 16 & 16 & 19 & 39 \\
\hline Arthur Schram & UvA & 17.68 & 14 & 17 & 21 & 24 & - \\
\hline Thorsten Beck & UvT & 17.66 & 15 & 18 & 22 & 25 & - \\
\hline Roel Beetsma & UvA & 17.55 & 16 & 19 & 19 & 22 & - \\
\hline Jan van Ours & UvT & 17.37 & 17 & 20 & 9 & 11 & 11 \\
\hline Arno Riedl & UM & 17.03 & 18 & 21 & 24 & 27 & - \\
\hline Philip Hans Franses & EUR & 15.42 & 19 & 22 & 3 & 5 & 3 \\
\hline Massimo Giuliodori & UvA & 14.78 & 20 & 24 & 31 & 38 & - \\
\hline Patrick Verwijmeren & EUR & 14.47 & 21 & 26 & 32 & 40 & - \\
\hline Eddy van Doorslaer & EUR & 14.23 & 22 & 28 & 18 & 21 & 26 \\
\hline Etienne de Klerk & UvT & 14.22 & 23 & 23 & 30 & 31 & 32 \\
\hline Han Bleichrodt & EUR & 14.22 & 24 & 27 & 26 & 30 & 30 \\
\hline Jos van Ommeren & VU & 14.09 & 25 & 29 & 23 & 26 & 20 \\
\hline Marius van Dijke & EUR & 13.81 & 26 & 30 & 28 & 34 & 36 \\
\hline Erik Verhoef & VU & 13.80 & 27 & 31 & 20 & 23 & 12 \\
\hline Maarten Lindeboom & VU & 13.46 & 28 & 33 & 37 & - & - \\
\hline Joep Sonnemans & UvA & 13.25 & 29 & 35 & 39 & - & - \\
\hline Robert Dur & EUR & 13.18 & 30 & 36 & 40 & - & - \\
\hline Deanne den Hartog & UvA & 13.18 & 31 & 37 & 38 & - & - \\
\hline Daan van Soest & VU & 13.07 & 32 & 38 & - & - & - \\
\hline Luc Renneboog & UvT & 12.88 & 33 & 40 & 29 & 32 & 22 \\
\hline Arjen van Witteloostuijn & UvT & 12.74 & 34 & 32 & 34 & 35 & 33 \\
\hline Matthijs van Veelen & UvA & 12.61 & 35 & 8 & - & 14 & - \\
\hline Marcel Timmer & RUG & 12.47 & 36 & - & - & - & - \\
\hline Eva Demerouti & TUE & 12.44 & 37 & - & 17 & 20 & 17 \\
\hline Peter Verhoef & RUG & 12.44 & 38 & - & 35 & 37 & 29 \\
\hline Andre Lucas & VU & 12.20 & 39 & - & - & - & - \\
\hline Owen o'Donnell & EUR & 12.19 & 40 & - & - & - & - \\
\hline
\end{tabular}

Table 2: Ranking based on alternative criteria 
significant contribution to economic thought and knowledge."9 The age criterion typically selects individuals with high rates of productivity, and indeed John Bates Clark Medal recipients are invariably impactful and prolific or, perhaps more accurately, prolific given exceptional impact. So, what then does prolific mean in numbers? Looking at the last five John Bates Clark Medal winners, apparently about 2-3 papers a year. ${ }^{10}$ Certainly not 5 a year, and most certainly not 20 a year.

What does this say about the method of the latest ESB ranking? When we take the last 5 winners of the John Bates Clark Medal, add them to the 2013 ESB database with their publications in the five years prior to the year they were awarded the medal, and rank them with the Dutch economists according to the published ESB criteria, their ranking would be unjustifiably poor. Only two of the five John Bates Clark Medalists would even make it into the Top 40, with the highest ranked only taking the 25 th spot. However, when we include them in our alternative ranking scheme and dream that they be appointed in the Netherlands, they occupy spots 1-4 and 7.

\section{Conclusion}

In many Dutch universities economists and business scholars have found their way to the top journals in their fields. This is something to cherish. We have argued that the latest ESB ranking of economists emphasizes research quantity over quality. Indeed, the last five John Bates Clark Medalists, although they were explicitly selected for their highly significant contributions to economic thought and knowledge, would not fare well in this ranking if judged by their publication records at the time of their awards. This concerns us greatly, not because the annual ranking of economists in the Netherlands is important by

\footnotetext{
${ }^{9}$ See https://www.aeaweb.org/honors_awards/clark_medal.php.

${ }^{10}$ The last five John Bates Clark Medal winners were Raj Chetty (2013), Amy Finkelstein (2012), Jonathan Levin (2011), Esther Duflo (2010), and Emmanuel Saez (2009).
} 
itself, but because its criteria have been chosen by the deans of the economists departments in the Dutch universities and are likely to reflect or even impact research, recruitment, and retainment policies in those departments.

Therefore, even though we are not sold on the idea that one should rank economists based on simple productivity statistics and scientometrics, we have proposed an alternative ranking that puts quality before quantity. This alternative ranking recognizes the five John Bates Clark Medalists for what they are, world leaders in economic research that would be some of the very best Dutch economists if they were appointed in the Netherlands. We hope and expect that Dutch economics departments recruit (especially junior) researchers who are enthusiastic about working hard on high quality research and allocate resources (including tenure-track faculty positions) to those who aspire to be as influential as the typical John Bates Clark Medalist. This requires that the deans abandon such criteria as those underlying the latest ESB ranking and explicitly recognize that it is generally not possible, at least not in business and economics, to produce more than 5 or so high-quality papers per year. We do not want to promote the idea of ranking Dutch economists per se, but we do believe that criteria like the ones underlying our alternative ranking are a better inspiration for our schools' policies than those chosen by the deans for the last ESB ranking. 


\section{References}

Bauwens, L. (2007). A new method to rank university research in economics in Belgium. CORE, mimeo.

Dolado, J. J., A. Garcia-Romero, and G. Zamarro (2003). Publishing performance in economics: Spanish rankings (1990-1999). Spanish Economic Review 5, 85-100.

Neary, J. P., J. A. Mirlees, and J. Tirole (2003). Evaluating economics research in Europe: an introduction. Journal of the European Economic Association 1, 1239-1249.

Phlippen, S. (2013). De economentop 40 2013. Economische Statistische Berichten 98(4674 \& 4675), 776-777.

Van Ours, J. C. and F. Vermeulen (2007). Ranking Dutch economists. De Economist 155, $469-487$.

West, J. D. and C. T. Bergstrom (2013). Eigenfactor.org: Ranking and mapping scientific knowledge. Accessed in December 2013 at http://www.eigenfactor.org. 


\section{University Library}

\section{- M M I E E R VA A gateway to Melbourne's research publications}

Minerva Access is the Institutional Repository of The University of Melbourne

Author/s:

Abbring, JH;Bronnenberg, BJ;Gautier, PA;van Ours, JC

Title:

Dutch Economists Top 40

Date:

2014-06-01

Citation:

Abbring, J. H., Bronnenberg, B. J., Gautier, P. A. \& van Ours, J. C. (2014). Dutch Economists Top 40. ECONOMIST-NETHERLANDS, 162 (2), pp.107-114. https://doi.org/10.1007/ s10645-014-9227-7.

Persistent Link:

http://hdl.handle.net/11343/283128 